\title{
Development of a continuous evaporation system for an API solution stream prior to crystallization
}

\author{
Phillip Roche ${ }^{1}$, Roderick Jones ${ }^{1}$, Brian Glennon ${ }^{2}$, and Philip Donnellan ${ }^{1}$ \\ ${ }^{1}$ University College Dublin \\ ${ }^{2}$ Affiliation not available
}

February 1, 2021

\begin{abstract}
A bubble column was investigated as a method to achieve a desired and controllable rate of evaporation of a pharmaceutical solution in continuous processing mode. Applying a developed thermodynamic model to predict the rate of evaporation, all predicted values achieved accuracies within the bounds of instrumentation errors. The model accounted for the measured effect of reduced vapor pressure caused by dissolved solids as a function of their concentration. A general method to obtain accurate measurement of this effect is introduced and applied, improving the accuracy of model predictions. Predicting the rate of evaporation using the developed model, consistent and repeatable evaporation rates ranging from $0.7-6.9 \mathrm{~g} / \mathrm{min}$ were achieved. Applying the column as a controllable evaporator, the concentration of a dilute feed stream was increased in a single equilibrium stage and coupled to a crystallizer. The configured system achieved a steady state of controllable operation over a duration of 5 hours
\end{abstract}

\section{Hosted file}

Manuscript - figs removed.pdf available at https://authorea.com/users/393179/articles/506857development-of-a-continuous-evaporation-system-for-an-api-solution-stream-prior-tocrystallization
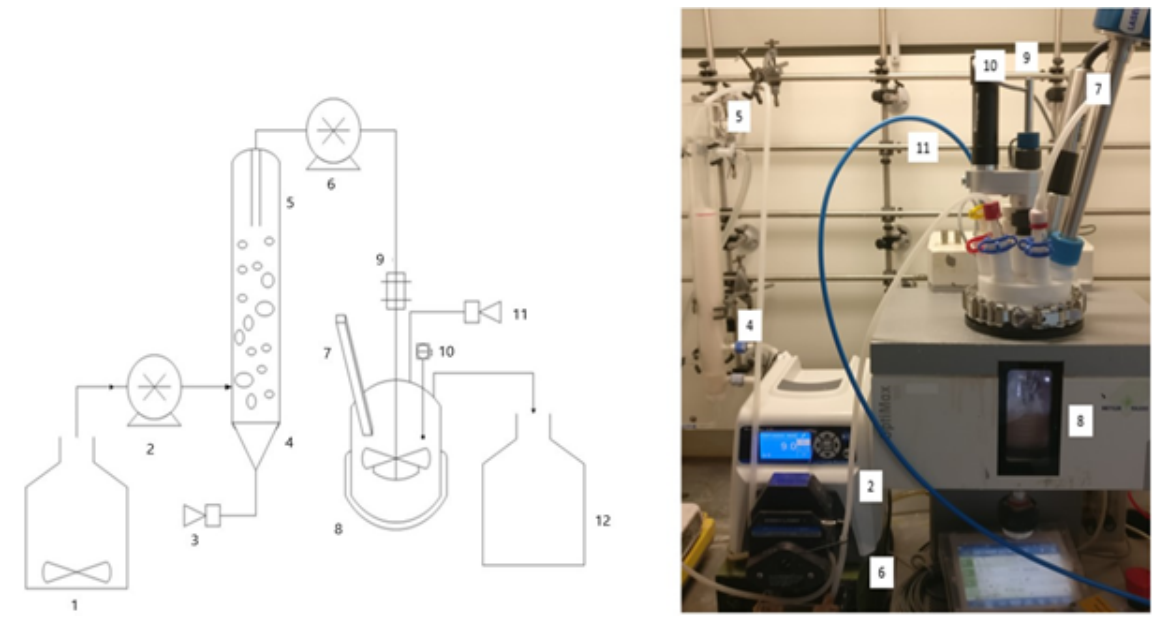

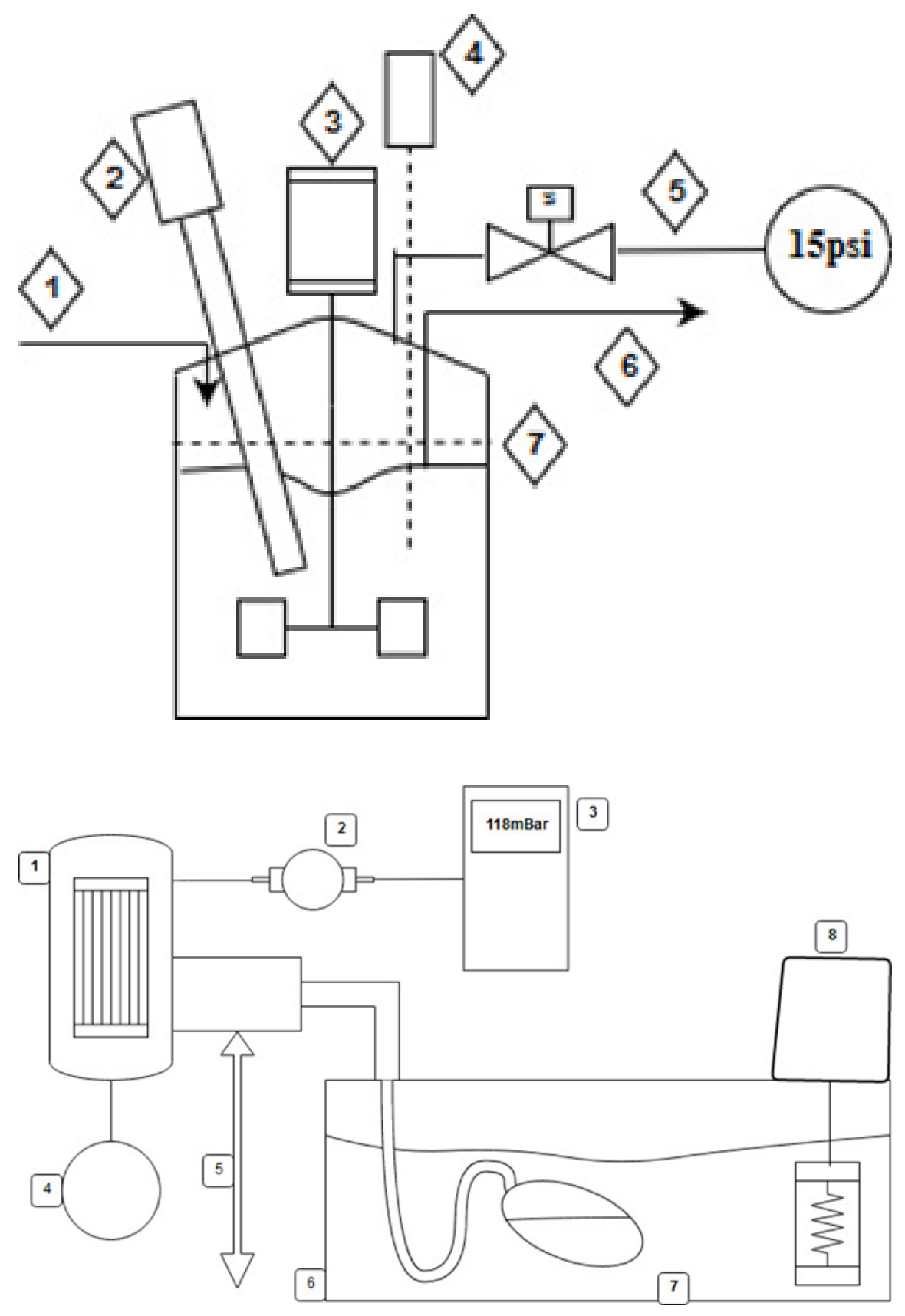

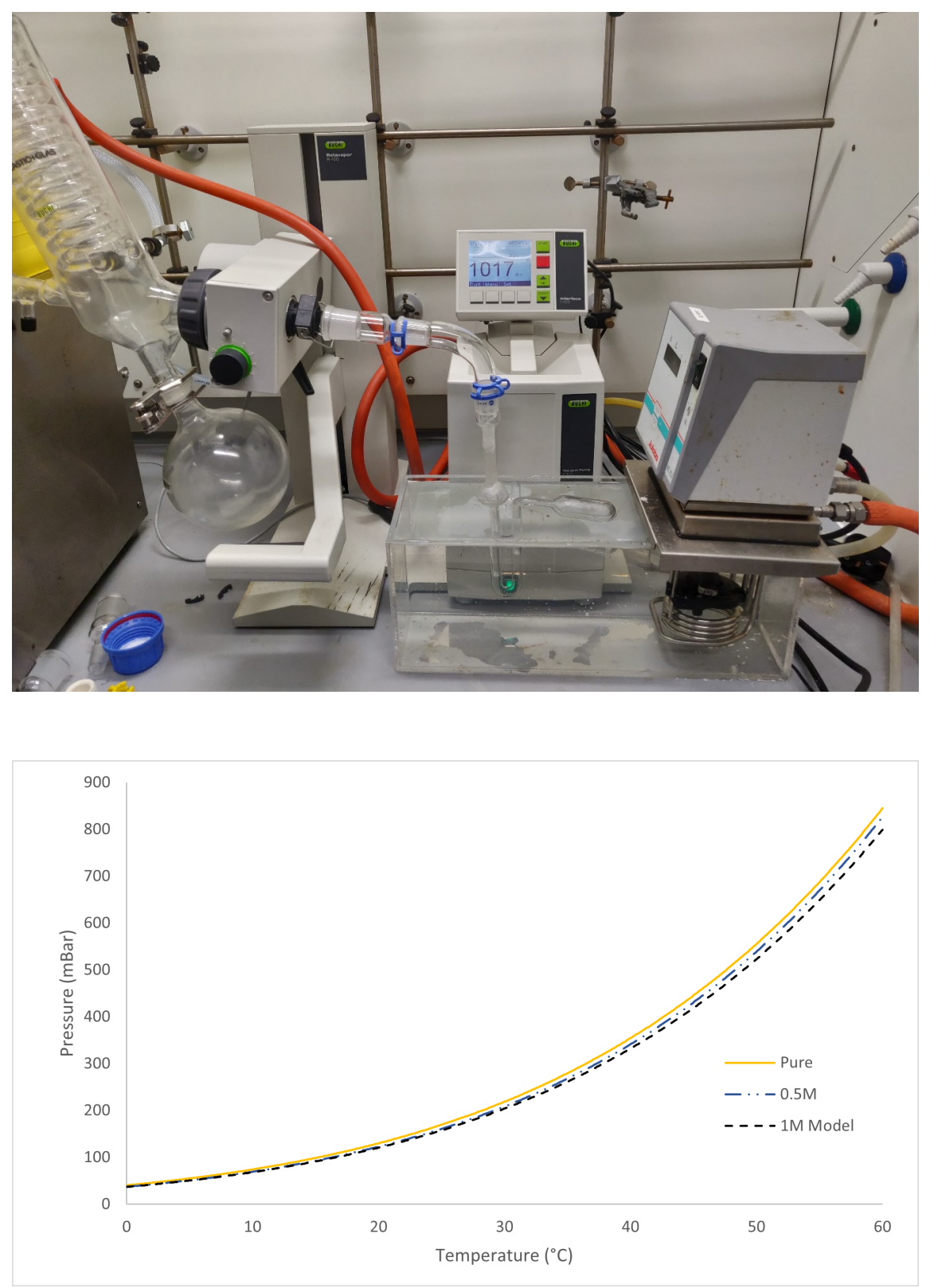

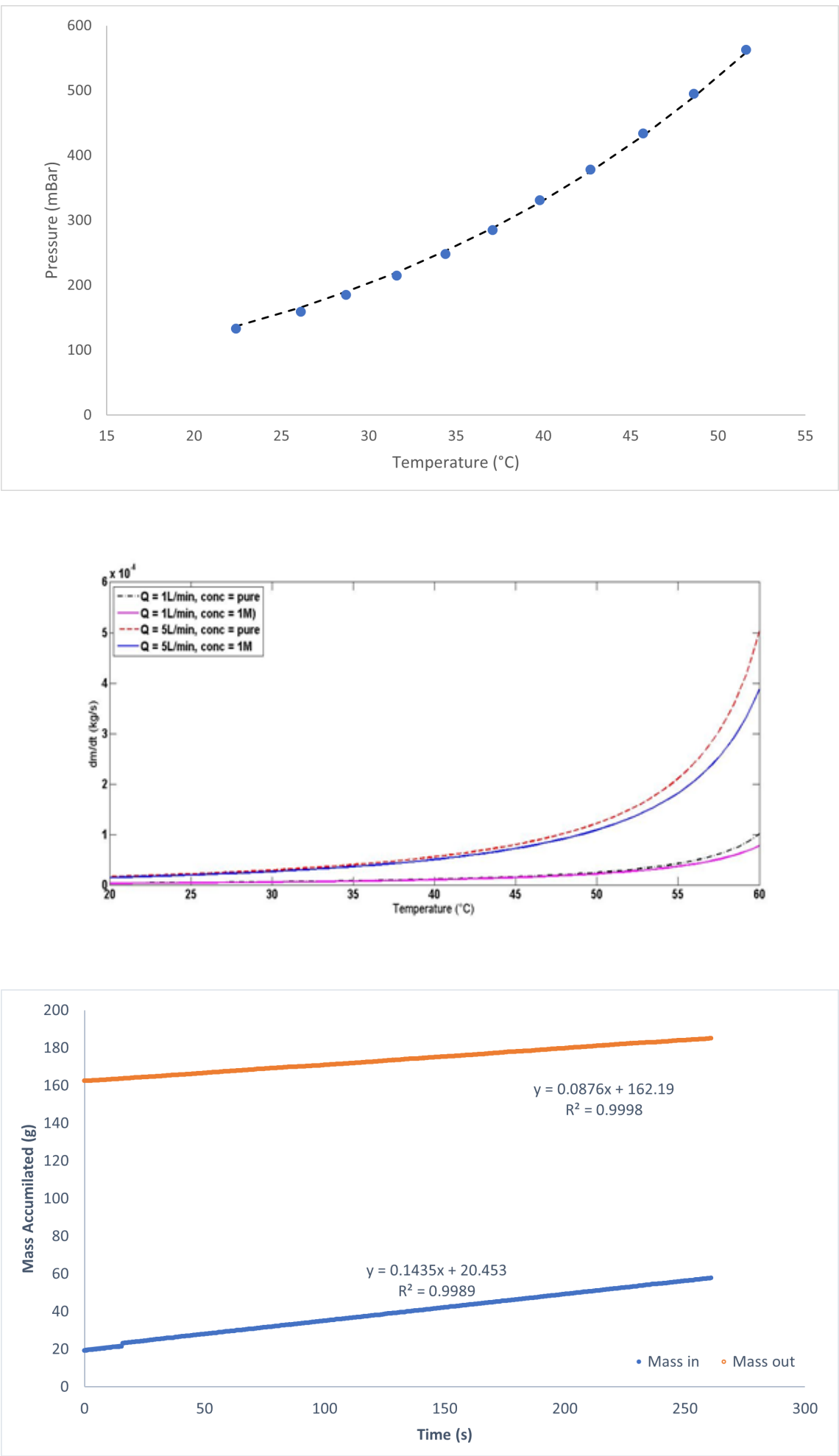

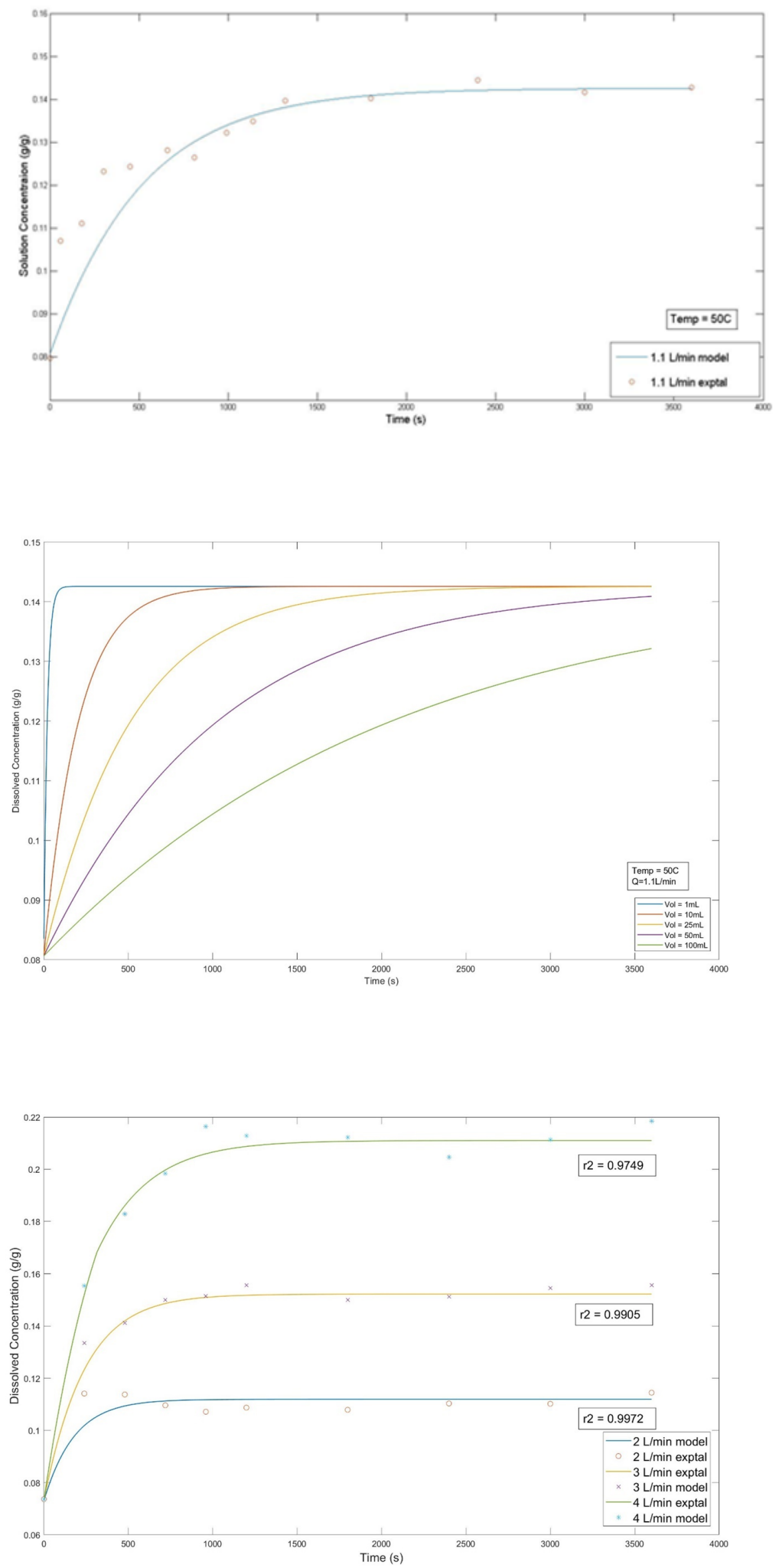

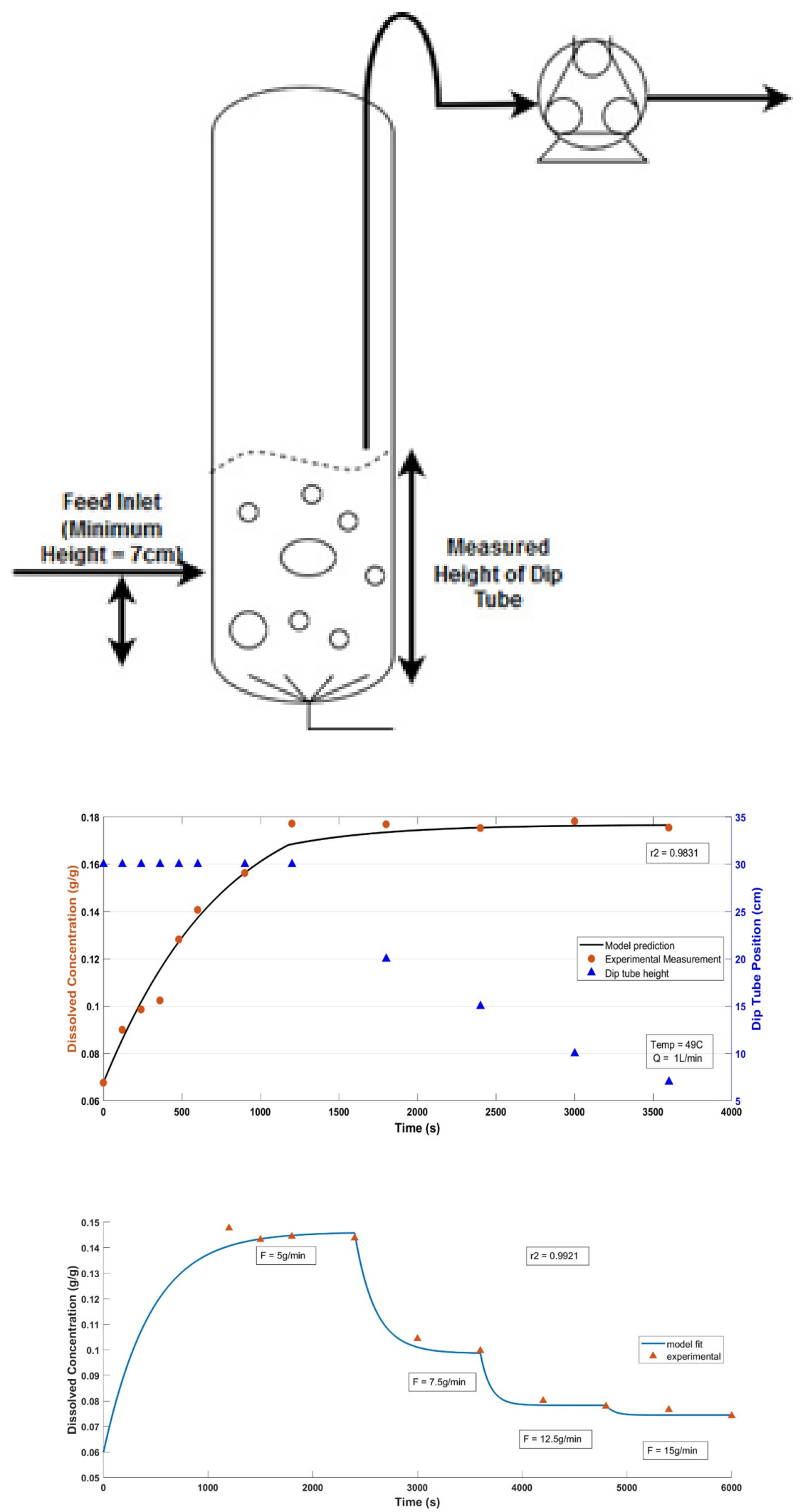

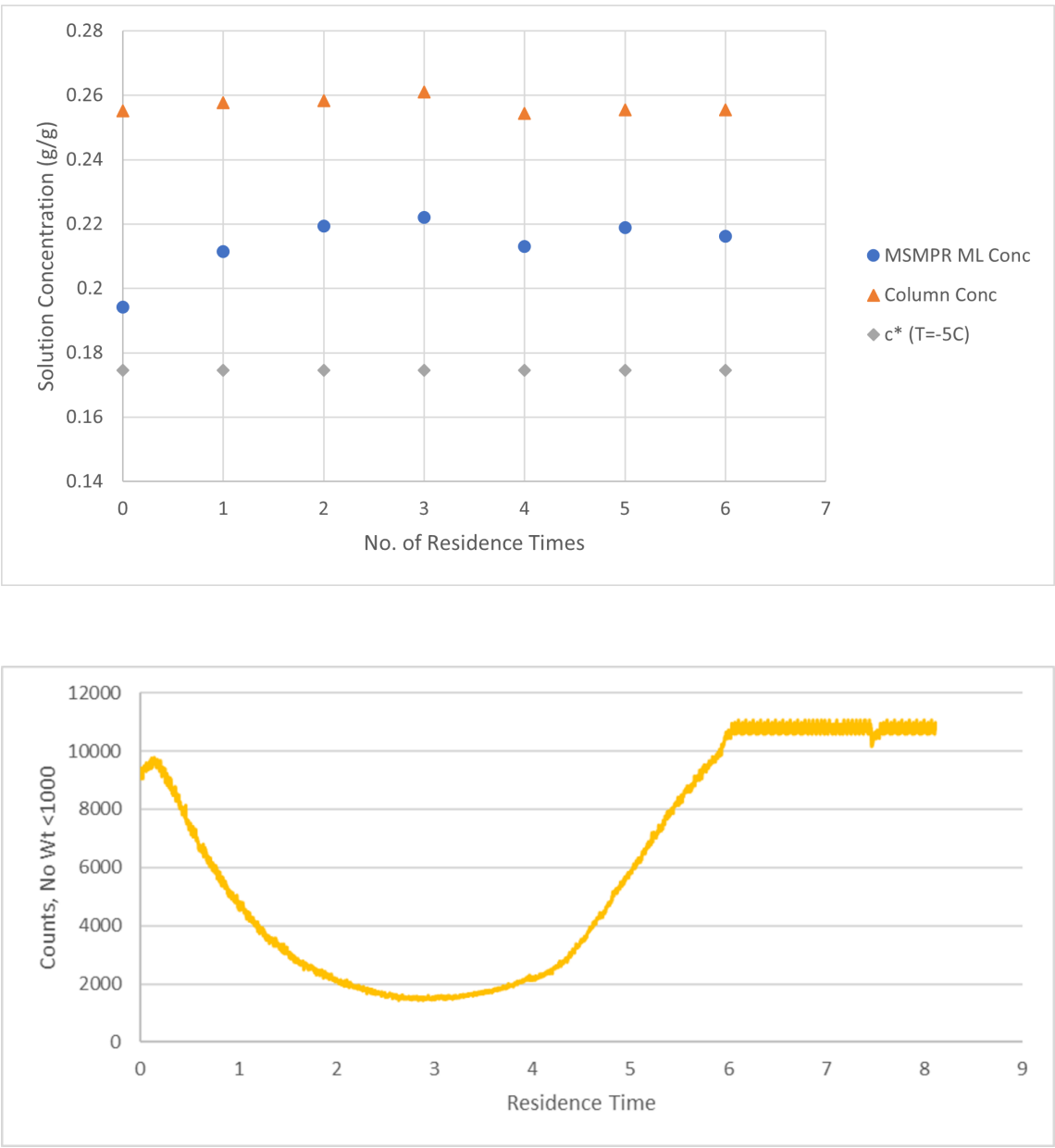

\section{Hosted file}

Tables.pdf available at https://authorea.com/users/393179/articles/506857-development-of-acontinuous-evaporation-system-for-an-api-solution-stream-prior-to-crystallization 